\title{
PCR-based survey of vector-borne pathogens in dogs in Dhaka, Bangladesh
}

\author{
M. H. Talukder ${ }^{1}$, A. MATSUU ${ }^{2}$, A. IGUCHI ${ }^{2}$, B. C. Roy ${ }^{1}$, N. NISHII ${ }^{3}$ and Y. HIKASA ${ }^{2}$ \\ ${ }^{1}$ Department of Parasitology, Bangladesh Agricultural University, Mymensingh-2202, Bangladesh, ${ }^{2}$ Department of \\ Veterinary Internal Medicine, Faculty of Agriculture, Tottori University, Koyama-Minami 4-101, Tottori 680-8553, Japan \\ and ${ }^{3}$ Department of Pharmacotherapeutics, Faculty of Agriculture, Tottori University, Koyama-Minami 4-101, Tottori \\ 680-8553, Japan, E-mail: mhtalukder03@yahoo.com
}

\begin{abstract}
To identify tick-borne pathogens in blood samples from 68 dogs were examined for Babesia, Anaplasma/Ehrichia, Mycoplasma, and Hepatozoon spp. by using a molecular tool. The detection of DNA was performed using specific primers for partial 16S rRNA or 18S rRNA sequence, and amplicon sequences were analyzed. Our investigation detected Babesia gibsoni (26 dogs) and Anaplasma sp. AnHI446 (2 dogs), Mycoplasma haemocanis (27 dogs), and an unknown Mycoplasma spp were detected (2 dogs), which was most closely related to Candidatus Mycoplasma turicensis, on the basis of phylogenetic analysis. Hepatozoon DNA could not be detected in this study.
\end{abstract}

Keywords: Tick-borne-pathogen, Babesia gibsoni, Mycoplasma haemocanis, Anaplasma sp. AnHI446

\section{Introduction}

Canine tick-borne diseases are an important problem, especially in tropical and subtropical regions. In Asia, tick-borne bacterial or parasitic infections by Babesia, Ehlichia, Anaplasma, Mycoplasma, and Hepatozoon species have been predominantly recognized. These pathogens are transmitted mainly by the Ixodid tick species from the genera Ixodes, Dermacentor, Rhipicephalus, Haemaphysalis, and Ambloymma. In South Asia, tick-borne diseases have been recognized since an early time, for example, Babesia gibsoni was first recognized in India (Patton, 1910) and Hepatozoon canis was first recognized in India (James, 1905). Although, the incidence of B. gibsoni was reported from Iran (Niak et al., 1973), there is little information about the current state of infections of dogs in the South Asia region. In Bangladesh, there have been no epidemiological studies regarding the prevalence of these infections among dogs. Using blood samples isolated from various sick dogs in the animal hospital in Dhaka, the capital of Bangladesh, we examined the state of infections of tick-borne diseases in dogs by using a molecular tool.

\section{Materials and Methods}

Peripheral blood samples from 68 dogs were randomly obtained from the animal hospital in Dhaka,

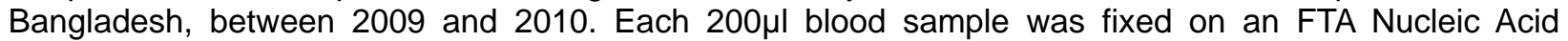
Collection Card (Whatman, UK) and stored at room temperature in the dark. DNA was extracted from the blood on the FTA Cards by using the Whatman FTA Card DNA Isolation Kit (Whatman, UK). Of the 68 dogs, 31 were female and 37 were male. Age ranged from 1 to 6 years (median, 3 years). There were 31 Mongrel dogs and 33 dogs of other breeds (Bulldogs: $n=8$, German shepherds: $n=6$, Greyhounds: $n=5$, Labrador Retrievers: $n=5$, Spaniels: $n=4$, Shih Tzu: $n=4$, and Chinese crested dog: $n=1$ ). The breed was not determined for 4 dogs. On physical examination, 7 of these were found to be healthy; 2 were pregnant; 11 were anemic; 17 were lethargic; 13 had dermatitis; and 10 had fever.

The sequences of the primers used to amplify Babesia spp., Anaplasma/Ehrichia spp., Mycoplasma spp., and Hepatozoon spp. are shown in Table 1. Polymerase chain reaction (PCR) was performed on $25 \mu$ of a mixture containing template DNA, $10 \mathrm{pmol}$ of each primer, $200 \mu \mathrm{m}$ deoxynucleoside triphosphate (dNTP), and 1.25 units of Taq DNA polymerase (TaKaRa, Shiga, JAPAN). PCR was repeated for 40 cycles with denaturation for $1 \mathrm{~min}$ at $94^{\circ} \mathrm{C}$; annealing at for 1 min at $55^{\circ} \mathrm{C}$ for Babesia spp. and Anaplasma/Ehrichia spp., $50^{\circ} \mathrm{C}$ for Mycoplasma spp., and5 $7^{\circ} \mathrm{C}$ for Hepatozoon spp.; and extension for $1 \mathrm{~min}$ at $72^{\circ} \mathrm{C}$. The PCR product was separated by electrophoresis using a $1.5 \%$ agarose gel with TBE 
buffer, stained with ethidium bromide, and photographed in ultraviolet light. The amplified DNA was purified using a commercial kit (QIAamp purification kit; Qiagen, USA) and sequenced directly (ABI PRISM 310 genetic Analyzer; Applied Biosystems, USA). The sequences were evaluated and edited using Genetyx Version. 10.0 (Genetyx, Co., Tokyo, Japan), and consensus sequences were submitted to a BLAST search (http://blast.ncbi.nlm.nih.gov/Blast.cgi) to determine the sequence identity in order to find orthologous sequences available in the GenBank database.

Table 1. Primer sets used for detection of DNA of tick borne pathogens in dogs in Bangladesh

\begin{tabular}{|c|c|c|c|c|c|}
\hline Pathogen & Gene & Primer & Sequence (5'-3') & fragment size & Reference \\
\hline \multirow[t]{2}{*}{ Babesia spp. } & 18S rRNA & & GTGAAACTGCGAATGGCTCA & \multirow{2}{*}{$650 \mathrm{bp}$} & \multirow{2}{*}{$\begin{array}{l}\text { Inokuma et al., } \\
2003 .\end{array}$} \\
\hline & & & CCATGCTGAAGTATTCAAGAC & & \\
\hline \multirow[t]{2}{*}{$\begin{array}{l}\text { Anaplasma/ } \\
\text { Ehrlichia spp. }\end{array}$} & 16S rRNA & EHR16SD & GGTACC $(\mathrm{C} / \mathrm{T}) \mathrm{ACAGAAGAAGTCC}$ & \multirow[t]{2}{*}{ 345bp } & \multirow{2}{*}{$\begin{array}{l}\text { Brown et al., } \\
2001 .\end{array}$} \\
\hline & & EHR16SR & TAGCACTCATCGTTTACAGC & & \\
\hline \multirow[t]{2}{*}{ Mycoplasma spp. } & 16S rRNA & fHF5 & AGCAGCAGTAGGGAATCTTCCAC & \multirow{2}{*}{ 674bp } & \multirow{2}{*}{$\begin{array}{l}\text { Messick et al., } \\
1998 .\end{array}$} \\
\hline & & rHF6 & TGCACCAACCTGTCACCTCGATAAC & & \\
\hline \multirow[t]{2}{*}{ Hepatozoon spp. } & 18S rRNA & HepF & ATACATGAGCAAAATCTCAAC & \multirow{2}{*}{ 666bp } & \multirow{2}{*}{$\begin{array}{l}\text { Inokuma et al., } \\
2002 .\end{array}$} \\
\hline & & HepR & CTTATTATTCCATGCTGCAG & & \\
\hline
\end{tabular}

\section{Results and Discussion}

Of the 68 dogs, 26(38.2\%) were positive for Babesia spp., from the results of PCR. The partial 18S rRNA gene sequences of these positive PCR products were determined using $602 \mathrm{bp}$ of the amplified product, excluding the primer region. BLAST analysis revealed that all the samples were $100 \%$ identical $(602 / 602)$ to the sequence of $B$. gibsoni Asia-2 (GenBank accession no.AF175301). PCR results of 2dogs (2.9\%) showed they were positive for Ehlichia/Anaplasma spp. The partial 16S rRNA gene sequences of these positive PCR products were determined using 304bpof the amplified region excluding the primer region. BLAST analysis revealed that both samples were 100\% identical to the partial 16S rRNA gene of Anaplasma sp. AnHI446 (GenBank accession no.AF497579). Twenty-nine dogs (42.6\%) were positive for Mycoplasma spp., from the PCR results. The partial 16S rRNA gene sequences of these positive PCR products were determined using a $627-\mathrm{bp}$ sequence of the amplicon excluding the primer region. BLAST analysis revealed that the 627-bp samples were 99.5-100\% (624-627/627) identical to the sequence of Mycoplasma haemocanis (GenBank accession no.EF416568, EF416567, EF416566), except in the case of 2 samples, which were both $89.6 \%$ (562/627) identical to $M$. haemocanis. The sequence of this strain was similar to that of Candidatus Mycoplasma turicensis (DQ464425, DQ464424) with 98.7\% (619/627) identity.

A phylogenetic tree of partial 16S rRNA genes for this unknown Mycoplasma isolate and other Mycoplasma species was constructed using neighbor-jointing analysis in MEGA 5.0 (Tamura et al., 2007) and is shown in Fig. 1. This Mycoplasma sp. was the most closely related to Candidatus Mycoplasma turicensis, but showed significant phylogenetic distance from $M$. haemocanis and Candidatus Mycoplasma haematoparvum, which are commonly recognized as canine pathogens. No dogs were positive for Hepatozoon spp. in this study.

Amongst the 68 dogs examined, $42(61.8 \%)$ dogs were positive for one or more of the pathogens. One dog was positive for B. gibsoni, M. haemocanis, and Anaplasma sp. AnHI446. Twelve dogs were positive for $B$. gibsoni and $M$. haemocanis, and one for B. gibsoni and Anaplasma sp. AnHI446. Twelve dogs were singly positive for $B$. gibsoni, 14 for $M$. haemocanis, and 2 for an unrecognized Mycoplasma sp. (Table 2). In this study, vector-borne pathogens were investigated in blood samples of dogs from Bangladesh. The infection rates in dogs with these pathogens, especially with $B$. gibsoni and $M$. haemocanis, were extremely high. Canine babesiosis is caused by a protozoan parasite of the genus Babesia, which is distributed worldwide. 


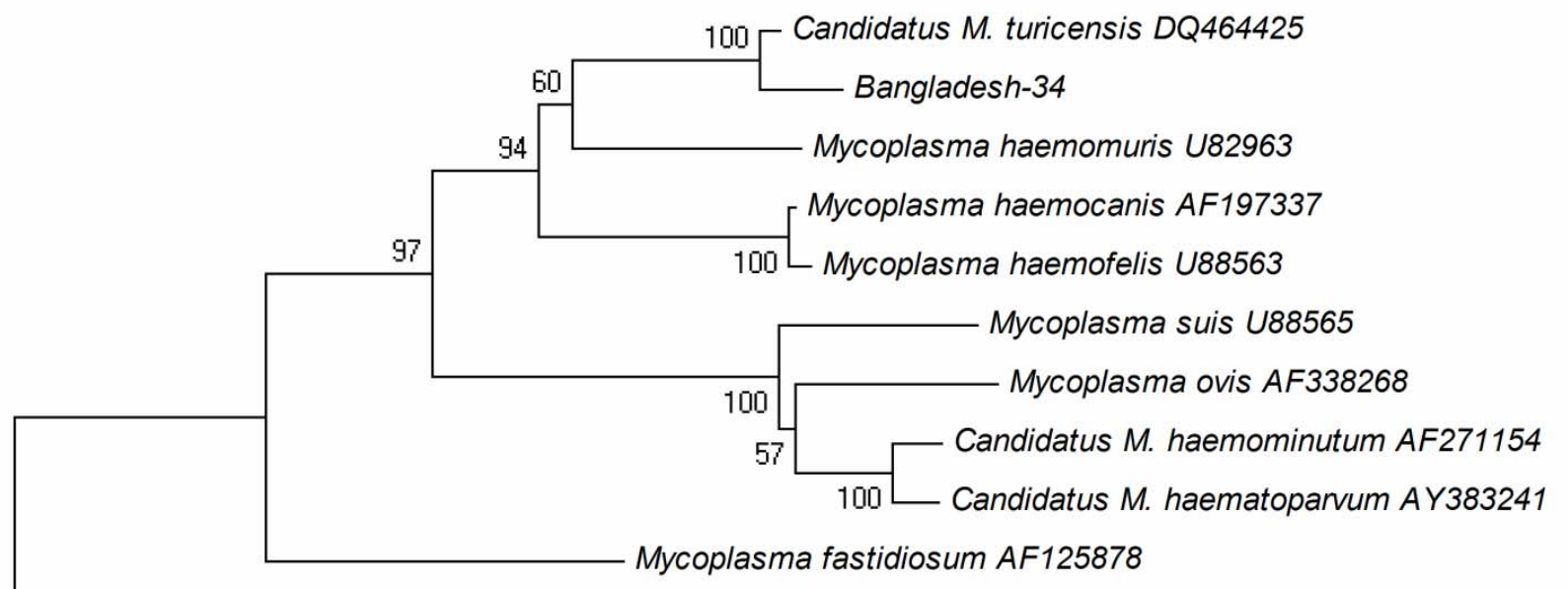

Anaplsma marginale M60313

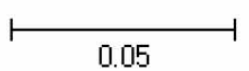

Fig. 1. Phylogenetic relationship between Mycoplasma detected in 2 Bangladesh dogs (Bangladesh-34) and other Mycoplasma species based on the partial sequences of the 16S rRNA gene. The neighbor-jointing method was used to construct the phylogenetic tree using the MEGA 5 program. The scale bar represents $0.05 \%$ divergence. The numbers at the nodes are the proportions of 100 bootstrap re-samplings that support the topology shown.

Table 2. Infection rates of agents in 68 dogs in Bangladesh examined by PCR

\begin{tabular}{|l|c|}
\hline PCR and sequencing & Number of dogs (\%) \\
\hline B. gibsoni+ M. haemocanis+ Anaplasma sp. AnHI446 & $1(1.5)$ \\
\hline B. gibsoni+ Anaplasma spp. AnHI1 & $1(1.5)$ \\
\hline B. gibsoni+ M. haemocanis & $12(17.7)$ \\
\hline B. gibsoni & $12(17.7)$ \\
\hline M. haemocanis & $14(20.6)$ \\
\hline Unknown Mycoplasma sp. & $2(3.2)$ \\
\hline None detected & $26(38.2)$ \\
\hline Total & $68(100)$ \\
\hline
\end{tabular}

Two species of Babesia have been traditionally identified as the principal cause of canine babesiosis, Babesia canis, which is large in size, and the small-sized Babesia gibsoni (Boozer and Macintire, 2003). However, with the development of new molecular methods, more piroplasmid species have been found as canine pathogens. These include the small piroplasms B. gibsoni (Kjemtrup et al., 2000); B. conradae (Kjemtrup et al., 2006); B. microti-like piroplasm (also referred to as Theileira annae (Camacho, 2006 and Zahker et al., 2000); Theileria spp. (Matjila et al., 2008); and the large piroplasms B. canis, B. vogeli, $B$. rossi, and an unidentified large-sized Babesia spp. (Solano-Gallego et al., 2012). In Asia, B. gibsoni and $B$. vogeli have been reported. In this study, $B$. gibsoni identical to $B$. gibsoni Asia-2 genotype was found to be dominantly distributed in Bangladesh.

M. haemocanis, formerly classified as a Haemobartonella species, has recently been positioned within the genus Mycoplasma by 16S rRNA analysis (Messick et al., 2002). This is a small, uncultivable, cell wall-lacking group of bacteria that can infect the red blood cells of mammalian species. In dogs, $M$. haemocanis and Candidatus Mycoplasma haematoparvum have been characterized as pathogens (Messick et al., 2002 and Sykeks et al., 2004). Infection with M. haemocanis, which is found worldwide, generally induces clinically significant anaemia, particularly in splenectomized or immunocompromised dogs (Inokuma et al., 2006; Novacco et al., 2010 and Ramos et al., 2010). However, in Asia, detailed 
epidemiological evidence has not been reported. It is found that $M$. haemocanis infection is dominant and has a high infection rate among dogs in Bangladesh. In addition, an unknown Mycoplasma sp. was detected in 2 dogs; this species is most closely related to Candidatus Mycoplasma turicensis, a bacterium that has been detected in cats worldwide (Willi et al., 2005 and Willi et al., 2006). In this study, we analyzed only the partial sequences of the 16S rRNA gene of the agent from these 2 dogs. To confirm the results of this study, pathogens from more dogs should be analyzed and compared to longer sequences of the 16S rRNA gene of this agent. Two dogs infected with Anaplasma spp. The sequences demonstrated a nucleotide identity of $100 \%$ with the $16 \mathrm{~S}$ rDNA gene of Anaplasma sp. AnH1446, which was obtained from Haemaphysalis lagrangei ticks collected from a bear in Thailand (Parola et al., 2003). This Anaplasma sp. AnHI446 is genetically similar to A. bovis (99.6\%) and A. phagocytophilum (96.5\%), and in the phylogenetic tree, this strain was thought to be contained in an A. bovis group (Parola et al., 2003). Although Sakamoto et al., (2010) has demonstrated A. bovis DNA in the peripheral blood of dogs, there are no reports demonstrating that the Anaplasma sp. AnHI1446 exhibits pathogenicity against animals or humans. Of the two infected dogs, one was infected with both $B$. gibsoni and $M$. haemocanis. This dog was in poor health. The other dog was infected with $B$. gibsoni, and its only clinical signs was dermatitis. It was not possible to determine whether this Anaplasma infection is associated with clinical pathogenicity.

In Bangladesh, more than a dozen of tick species have been recorded in domestic animals. The common species infesting dogs in Bangladesh have been reported as Boophilus microplus, Amblyomma variegatum, Rhipicephalus sanguineus, and Haemaphysalis bispinosa (Ghosh et al., 2007). These ticks can act as a vector for Babesia, Mycoplasma, and Anaplasma spp. It is possible that this is a cause of concurrent infections.

\section{Conclusion}

In conclusion, our molecular study revealed high infection rates of tick-borne diseases in dogs living in Dhaka, Bangladesh. Detailed studies to correctly identify the exact vector tick are required.

\section{References}

Boozer A.L. and Macintire, D.K. 2003. Canine babesiosis. Veterinary Clinics of North America: Small Animal Practice, 33:885-904.

Brown, G.K., Martin, A.R., Roberts, T.K. and Aitken, R.J. 2001. Detection of Ehrlichia platys in dogs in Australia. Australian Veterinary Journal, 79: 552-553.

Camacho-Garcia, A.T. 2006. Piroplasma infection in dogs in northern Spain. Veterinary Parasitology, 138:97-102.

Gal A., Loeb, E., Yisaschar-Mekuzas, Y. and Baneth, G. 2008. Detection of Ehrilichia canis by PCR in different tissues obtained from dogs surveyed for naturally occurring canine monocyticehrlichiosis. Veterinary Journal, 175:212-217.

Ghosh, S., Bansal, G.C., Gupta, S.C., Ray, D., Khan, M.Q., Irshad H., Shahiduzzaman, M., Seitzer, U. and Ahmed, J.S. 2007. Status of tick distribution in Bangladesh, India and Pakistan. Parasitology Research, 101: S207-216.

Inokuma, H., Okuda, M., Ohno, K., Shimoda, K. and Onishi, T. 2002. Analysis of the 18S rRNA gene sequence of a Hepatozoon detected in two Japanese dogs. Veterinary Parasitology, 106:265-271.

Inokuma, H., Yoshizaki, T., Shimada, Y., Sakata, Y., Okuda, M. andOnishi, T. 2003. Epidemiological survey of Babesia species in Japan performed with specimens from ticks collected from dogs and detection of new Babesia DNA closely related to Babesiaodocoilei and Babesia divergens DNA. Journal of Clinical Microbiology, 41:3494-3498.

Inokuma, H., Oyamada, M., Davoust, B., Boni, M., Dereure, J., Bucheton, B., Hammad, A., Watanabe, M., Itamoto, K., Okuda, M. and Brouqui, P. 2006. Epidermiological survey of Ehrlichiacanis and related species infection in dogs in easetern Sudan. Annals of the New York Academy of Sciences, 1078:461-463.

James, S.P. 1905. On a parasite found in the white corpuscles of the blood of dogs. Scientific Mem. Officers Med. \& Sanitary Depts. Gov. India, 14:1-12.

Kjemtrup,A.M., Kocan, A.A., Whitworth,L., Meinkoth, J., Birkenheuer, A.J., Cummings, J., Boudreaux, M.K.,Stockham, S.L., IrizarryRovira, A. and Conrad, P.A. 2000. There are at least three genetically distinct small piroplasms from dogs. International Journal for Parasitology, 30:1501-1505.

Kjemtrup, A.M., Wainwright, K., Miller, M., Penzhorn, B.L. and Carreno, R.A. 2006. Babesiaconradae, sp. Nov. a small canine Babesia identified in California. Veterinary Parasitology, 31:103-111. 
Matjila, P. T., Leisewitz, A. L., Oosthuizen, M. C., Jongejan, F. andPenzhorn, B. L. 2008. Detection of a Theileria species in dogs in South Africa. Veterinary Parasitology, 157:34-40.

Messick, J.B., Berent, L.M. and Cooper, S.K. 1998. Development and evaluation of a PCR- based assay for detection of Haemobartonellafelis in cats and differentiation of $H$. felis from related bacteria by restriction fragment length polymorphsm analysis. Journal of Clinical Microbiology, 36:462-466.

Messick J.B., Walker, P.G., Raphael, W., Berent, L. and Shi, X. 2002. 'Candidatusmycoplasma haemodidelphidis' sp. nov., 'Candidatus mycoplasma haemolamae' sp. nov. and Mycoplasma haemocaniscomb. nov., haemotrophic parasites from a naturally infected opossum (Didelphisvirginiana), alpaca (Lama pacos) and dog (Canisfamiliaris): phylogenetic and secondary structural relatedness of their 16S rRNA genes to other mycoplasmas. International Journal of Systematic and Evolutionary Microbiology, 52:693-698.

Niak, A., Anwar, M. and Khatibi, S. 1973. Canine babesiosis in Iran. Tropical Animal Health and Production, 5:200-201.

Novacco, M., Meli, M.L., Gentilini, F., Marsilio, F., Ceci, C., Pennisi, M.G., Lombardo, G., Lloret, A., Santos, L., Carrapiço, T., Willi, B., Wolf, G., Lutz, H. and Hofmann-Lehmann, R. 2010. Prevalence and geographical distribution of canine hemotropic mycoplasma infections in Mediterranean countries and analysis of risk factors for infection. Veterinary Microbiology, 19: 276-284.

Patton, W. S. 1910. Preliminary report on a new piroplasm (Piroplasma gibsoni sp. nov.) found in the blood of the hounds of the Madras Hunt and subsequently discovered in the blood of the jackal Canis aureus Bulletin de la Societe de Pathologie Exotique, 3:274-280.

Parola, P., Cornet, J.P., Sanogo, Y.O., Miller, R.S., Thien, H.V., Gonzalez, J.P., Raoult, D., Telford, S.R. and Wongsrichanalai, C. 2003. Detection of Ehrlichia spp., Anaplasma spp., Rickettsia spp., and other eubacteria in ticks from the Thai-Mynmar border and Vietm. Journal of Clinical Microbiology, 41: 1600-1608.

Ramos, R., Ramos, C., Araujo, F., Oliveira, R., Souza, I., Pimentel, D., Galindo, M., Santana, M., Rosas, E., Faustino, M. and Alves, L. 2010. Molecular survey and genetic characterization of tick-borne pathogens in dogs in metropolitan Recife (northeastern Brazil). Parasitology Research, 107:1115-1120.

Sakamoto, L., Ichikawa, Y., Sakata, Y., Matsumoto, K. and Inokuma, H. 2010. Detection of Anaplasmabovis DNA in the peripheral blood of domestic dogs in Japan. Japanese Journal of Infectious Diseases, 63:394-352.

Solano-Gallego, L., Baneth, G. Babesiosis in dogs and cats-expanding parasitological and clinical spectra. Veterinary Parasitology (In press)

Sykeks, J.E., Bailiff, N.L., Ball, L.M., Foreman, O., George, J.W. and Fry, M.M. 2004. Identification of a novel hemitropic mycoplasma in a splenectmized dog with hemic neoplasia. Journal of the American Veterinary Medical Association, 224:1946-1951.

Tamura, K., Dudley, J., Nei, M.\& Kumar, S. 2007. MEGA4: Molecular Evolutionary Genetics Analysis (MEGA) software version 4.0. Molecular Biology and Evolution, 24: 1596-1599.

Willi, B., Boretti, F.S., Cattori, V., Tasker, S., Meli, M.L., Reusch, C., Lutz, H. and Hofmann-Lehmann, R. 2005.Identification, molecular characterization, and experimental transmission of a new hemoplasma isolate from a cat with haemolytic anemia in Switzerland. Journal of Clinical Microbiology, 43:2581-2585.

Willi, B., Tasker, S., Boretti, F.S., Doherr, M.G., Cattori, V., Meli, M.L., Lobetti, R.G., Malik, R., Reusch, C.E., Lutz, H.andHofmannLehmann, R. 2006. Phylogenetic analysis of "Candidatus Mycoplasma turicensis" isolates from pet cats in the United Kingdom, Australia, and South Africa, with analysis of risk factors for infection. Journal of Clinical Microbiology, 44:44304435.

Zahker, M., Rinder, H., Schein, E. and Gothe, R. 2000. Detection of a new pathogenic Babesia microti-like species in dogs. Veterinary Parasitology, 89:241-248. 